\title{
Sistemas regionais de proteção aos direitos humanos: aspectos fundamentais
}

\section{REGIONAL SYSTEMS PROTECTION OF HUMAN RIGHTS: FUNDAMENTALS}

\author{
Sérgio Tibiriça* \\ Giovana Eva Matos Farah**
}

Resumo: O presente ensaio apresenta como objeto de pesquisa o processo histórico da internacionalização dos direitos humanos com enfoque nos sistemas regionais. O propósito do trabalho também compreende a busca de subsídios para a construção de um novo conceito de proteção dos direitos humanos a partir das violações contidas nos casos contenciosos. O desenvolvimento da investigação é capitaneado pelos elementos históricos dos direitos humanos, fundados na evolução particular de cada sistema regional, compreendendo, deste modo, as funções desempenhadas por seus órgãos.

Palavras-chave: Direito Internacional; Direitos humanos; Sistemas regionais; Historicidade.

Abstract: This paper presents an object of research the historical
process of the internationalization of human rights with a focus
on regional systems. The purpose of the work also includes
seeking grants for the construction of a new concept of protection
of human rights from violations contained in litigations. Expanded
research is spearheaded by the historical elements of human
rights grounded in the particular evolution of each regional
system, comprising thus the functions performed by its organs.

Keywords: International Law; Human rights; Regional systems;

* Sérgio Tibiriça. Doutor em Historicity. Sistema Constitucional de Garantias pela ITE (2011). Professor titular de Teoria Geral do Estado da FDPP das Faculdades Integradas Antônio Eufrásio de Toledo. sergio@unitoledo.br

** Giovana Eva Matos Farah: Bacharel em Direito das Faculdades Integradas

Antônio Eufrásio de Toledo. giovanafarah32@hotmail.com 
"Os direitos não nascem todos de uma vez. Nascem quando devem ou podem nascer". Norberto Bobbio

\section{INTRODUÇÃO}

A presente pesquisa tratou de enfatizar uma das questões teóricas fundamentais do Direito Internacional dos Direitos Humanos e, por conseguinte, considerada uma das maiores exigências intelectuais de nosso tempo: $\mathrm{O}$ ato de repensar sobre o tratamento jurídico-normativo-histórico nas sociedades civis que compõem os sistemas regionais de direitos humanos. Foram usados além do método histórico, os dedutivos e indutivos por meio de pesquisas doutrinárias nacionais e estrangeiras, bem como de tratados internacionais de direitos humanos e jurisprudência da Corte Interamericana.

Discorreu-se, portanto, de uma abordagem geral sobre a investigação histórica dos direitos humanos nos âmbitos regionais, voltado a uma elaboração cognitiva sobre os direitos fundamentais violados pelo Estado sob escorço da defesa de condições mínimas e dignas, tanto na esfera constitucional como na internacional. Mostrou-se como é possível defender a dignidade do ser humano de diversas maneiras.

O objeto desta pesquisa foi derivado de uma concepção plural da humanidade que pretendemos, nas entrelinhas, resgatar através do conhecimento da evolução dos direitos humanos por meio da experiência doutrinaria e jurisprudencial da Corte Interamericana, bem como, de outras Cortes regionais de proteção dos direitos humanos.

Nessa diapasão, traçamos um panorama acerca da evolução dos direitos humanos, com o objetivo de demonstrar que o ser humano sempre tentou preservar seus valores mais valiosos, tais quais por meio da promoção dos direitos essenciais a preservação da vida e convivência em sociedade, resultando nos sistemas regionais de direitos humanos.

Assim, após uma breve apresentação da evolução dos direitos humanos, dissertou-se sobre a importância dos sistemas regionais, para então depois dissertar sobre cada sistema regional, como acabamento doutrinário do tópico anterior, restando, deste modo, finalizar a pesquisa tratando das particularidades mais importantes de cada sistema regional. 
Por fim, teceu-se sobre o aperfeiçoamento institucional diagnosticado em cada sistema regional, principalmente, no que tange sobre a evolução dos instrumentos internacionais que regem estes sistemas, bem como sobre o cumprimento das sentenças nestes sistemas frente a responsabilização internacional do Estado.

A justificativa concernente à metodologia utilizada tem como vértice os bens jurídicos nos instrumentos internacionais de proteção aos direitos humanos, a partir dos entendimentos inferidos dos casos contenciosos de violações dos direitos humanos nos sistemas regionais.

\section{UMA BREVE HISTÓRIA DA EVOLUÇÃO DOS DIREITOS HUMANOS}

Desde as sociedades duradouras, mesmo nos mais remotos tempos, o homem louva a preservação da evolução de seu maior potencial e procura organiza sua vida em grupo. Em tais sociedades construídas sobre estas medidas, as pessoas crescem e prosperam em direção a verdade e justiça, mas deixam contribuições importantes.

Assim, cada período do tempo se destaca na História por suas ideias, conquistas e descobertas surgidas em sua época. Atribuem-se, deste modo, certos desígnios para estas eras, como: A era da pedra, do fogo, a idade das luzes, revolução industrial e constitucionalismo. Mas, existem ideias, descobertas e conquistas que por serem tão significantes, ultrapassaram os limites de sua época e se perpetuaram na expectativa do homem, visando a busca da felicidade e a titularidade de direitos.

Assim, o direito internacional dos direitos humanos surgiu como disciplina autônoma no pós Segunda-Guerra, embora tenha como antecedente o direito humanitário. As atrocidades cometidas contra o ser-humano, instrumentalizado, então, como arma de guerra desprovida de dimensão capacitante da razão, convidou, por assim dizer, a comunidade internacional a uma profunda reflexão sobre o papel do homem no mundo contemporâneo e a necessidade dos estados em tutelar os bens mais essenciais à condição humana conforme anotam Norberto Bobbio (2004, p. 26) ${ }^{1}$, Danièle Lochak (2005, p. 06) ${ }^{2}$, Flávia Piovesan

\footnotetext{
Bobbio (2004, p. 26) defende que os direitos não nascem todos de uma vez. Nascem quando devem ou podem nascer.

2 Luchak (2006, p. 06), remontava: “' (...) les droits de l'homme ne sont ni éternels ni immuables lls sont travailles par una serie de constradictions, de tensions, affectés par una dynamique que les amène à evoluer sans cesse. Les droites de l'homme ont une histoire - une histoire qui n'est pas achevée et qui continue à s'écrire encore aujoud'hui".
} 
(2008, p. 18)³, Valério Mazzuoli (2002, p. 48), Cançado Trindade (1991, p.23) Herkenhoff (1997, p. 15), Eloísa Arruda (2008, 31-33)4.

Assim, o homem passou a ser visto como sujeito de direitos e objeto de tutela pelo direito internacional, que passou a ser chamado de direito internacional dos direitos humanos. Tal alteração de paradigmas foi simbolicamente coroada pela Declaração Universal dos Direitos Humanos.

Captando essa alteração de paradigmas no direito internacional, os estados que compõem organizações regionais criaram os sistemas regionais de proteção aos direitos humanos para, eficazmente, atingir o ideal de justiça e garantir a proteção de direitos inerentes à pessoa humana, conforme explica José Francisco Rezek (1989, p.158), Celso Lafer (2006, p. 13-32), Kathryn (1993, p. 441), André Pereira e Fausto Quadros (1993, p.661), Hector Fix-Zamudio (1991, p. 184).

Por fim, vislumbrou-se que a criação do sistema regional interamericano, surgiu como um fator protetor dos direitos basilares do homem na sociedade.

\section{OS SISTEMAS REGIONAIS DE PROTEÇÃO AOS DIREITOS HUMANOS}

Para entender a questão do movimento de internacionalização dos direitos humanos, é preciso antes compreender a situação dos direitos na Segunda guerra mundial (1939 - 1945), que acabou sendo uma consequência da Primeira guerra mundial (1914-1918).

Vários líderes nacionais, principalmente da Itália fascista de Benito Mussolini e a Alemanha nazista de Adolf Hitler, sacrificaram milhares de vidas em nome de um ideal que não respeitava o valor e a dignidade da pessoa humana, sendo que, com o final da guerra, a comunidade internacional atentouse para a preservação destes direitos, levantando o estandarte dos direitos humanos. Todavia, o absolutismo monárquico japonês também foi responsável por graves violações dos direitos humanos durante a Segunda guerra.

\footnotetext{
3 Nesta acepção ideológica, Flávia Piovesan (2000, p.18) afirma que é neste cenário que se desenha o esforço de reconstrução dos direitos humanos, como paradigma e referencial ético a orientar a ordem internacional contemporânea. Se a $2^{\circ}$ guerra mundial significou a ruptura com os direitos humanos, o pós-guerra deveria significar sua reconstrução.

4 Eloísa de Souza Arruda (2008, 31 - 33) parte do postulado de que todos os homens são iguais em direitos e dignidade, as barreiras de soberania nacional dos Estados foram rompidas, evoluindo a humanidade para uma ótica internacional e globalizada, para melhor garantir a implementação e o respeito aos direitos humanos. O individuo passou a gozar de status de sujeito de direitos internacionais, independentemente do Estado de origem.
} 
Desde o pós-guerra, a carga valorativa dos direitos humanos aumentou, sofrendo uma extensa expansão de internacionalização na comunidade global, ensejando-se, assim, nos sistemas regionais de proteção aos direitos humanos.

Deste modo, após a segunda guerra mundial, na visão jurídica, surgiu a necessidade de se criar mecanismo, instituições e instrumentos voltados à proteção e a defesa destes direitos. No início, não havia órgãos que implementassem e fizessem valer o cumprimento destes direitos, muito menos existia a capacidade processual no plano internacional (Amaral Junior, 2002, p.53) .

Assim, com a inauguração dos tratados internacionais e o assentamento da ONU, iniciou-se uma longa peregrinação rumo ao garantivismo dos direitos humanos e fundamentais, sendo considerada esta época como uma arquitetura protetiva internacional, conforme afirma Piovesan (2006, p. 133) .

Atualmente, existem três sistemas regionais de proteção aos direitos humanos: Europeu, Africano e Interamericano.

Cada um possui particularidades e semelhanças, destinadas a um só fim: A promoção dos direitos humanos.

Atualmente, estes sistemas regionais aumentaram exponencialmente soluções aos casos que envolviam violações aos direitos humanos contidos nos principais tratados internacionais. O acesso à justiça internacional, por meio da capacidade processual de se postular perante a justiça internacional tem ganho grande espaço no cenário dos sistemas regionais, possibilitando as comissões a terem conhecimento sobre os casos.

\subsection{O Sistema interamericano: órgãos e funções}

O sistema interamericano de direitos humanos foi criado pela Organização dos Estados Americanos (OEA), sendo composto por dois principais órgãos: A Corte e a Comissão Interamericana de Direitos Humanos.

O primeiro funciona como órgão de natureza jurisdicional, enquanto o segundo ocupa-se do processamento de petições de interposição perante a Corte.

Assim, quando surgir uma violação dos direitos humanos inseridos no âmbito de proteção normativa dos instrumentos tutelados pelo sistema

\footnotetext{
5 AMARAL Jr., Alberto do. A proteção internacional dos direitos humanos. Revista de informação legislativa, ano 39, n. 155, julho/setembro, 2002.

${ }^{6}$ PIOVESAN, Flávia. Direitos humanos e justiça internacional: Um estudo comparativo dos sistemas regionais europeu, interamericano e africano. São Paulo: Saraiva, 2006.
} 
interamericano, acionar-se-á o acesso à justiça perante a comissão, após o prévio exaurimento dos recursos internos, órgão previamente e legitimamente responsável por receber e processar petições na fase pré-jurisdicional, conforme anotam Héctor Fix-Samudio (1997, p. 227) 7 , André de Carvalho Ramos (2001, p. 57-58), Cançado Trindade (2003, p.34-35), Jean Arrighi (2004, p. 52).

Portanto, as violações de direitos humanos começaram a ser apuradas com mais rigor e resolvidas segundo os critérios normativos regionais, maximizando a busca pela efetiva justiça.

Uma das suas competências é a de, vigilantemente, examinar as comunicações de sujeitos, grupos de indivíduos ou entidades não governamentais em cada um dos Estados-membros da OEA, sobre as propagações de violações de direitos humanos previstos em instrumentos do sistema interamericano, ao qual o Estado membro seja parte, conforme é prelecionado precisamente por André Ramos (2002, p.229-238), Flávia Piovesan (2006, p.232-233), Luiz Flávio Gomes e Valério Mazzuoli (2006, p.427-437). Deste modo, a competência do sistema interamericano deixou de transparecer uma ideia de órgão burocrático para, eminentemente, promover e disponibilizar o acesso à justiça a nível internacional.

\subsection{O sistema europeu: órgãos e funções}

O sistema elaborado na Europa é o mais antigo em funcionamento, pois acompanhou a criação da União Europeia, que começou com os tratados de carvão e do aço e também a comunidade chamada BENELUX, integrada por Bélgica, Holanda e Luxemburgo. Por isso, a contribuição do modelo é importante para a abordagem dos direitos humanos em nível regional.

A importância de se conhecer outros sistemas regionais, além do interamericano, indicado por Valério Mazzuoli (2010, p. 824-842), importa no estudo do sistema europeu de direitos humanos, sob aspecto de seus órgãos e funções.

Esse sistema, conduzido pelo teor da convenção europeia foi um importante vetor na promoção e defesa dos direitos humanos no âmbito europeu pós-

\footnotetext{
Héctor Fix-Samudio (1997, p. 227) anota que a Comissão Interamericana criada em 1959, é o primeiro órgão efetivo de proteção dos direitos humanos. Embora com certas atribuições restritas, a Comissão realizou uma frutífera e notável atividade de proteção aos direitos humanos, incluindo a admissão e investigação de reclamações de indivíduos e de organizações não governamentais, inspeções nos territórios dos Estados-membros e solicitações de informes, com o que logrou um paulatino reconhecimento.
} 
segunda guerra, objetivando, por assim dizer, na tutela dos direitos de todas as pessoas, independente de nacionalidade ou outra condição qualquer, conforme fundamenta Franz Mastcher (ano, p.253), Héctor Gros Espiel (ano, p. 412), Jorge Miranda (2009, p. 286) e Jorge Bacelar (2005, p.463).

O sistema europeu é formado pela Corte Europeia e pelo Comitê de ministros da Europa.

A corte europeia, criada na data de 20 de abril de 1959, onde emitiu sua primeira sentença no caso Lawless versus Irlanda ${ }^{8}$ e, desde então, modificou e influenciou a jurisprudência de vários tribunais do mundo.

Este segundo órgão que teve suas funções modificadas pelo protocolo $\mathrm{n}^{\circ} 11$, não perdeu a função de supervisão sob as sentenças da Corte, pois se entendeu que esta função deve estar endereçada a um órgão de composição politica, capaz de influenciar os Estados a melhor cumprirem as decisões emitidas pela Corte, conforme assevera Cançado trindade (1993, p.124-125) e Paul Mahoney e Soren Prebensen (1993, p.636). ${ }^{9}$

Portanto, trata-se de uma abordagem de um aprimoramento na busca pela efetivação dos direitos humanos, pois quando mais órgãos jurisdicionais e não jurisdicionais forem criados, melhores serão as condições, em tese, para a proteção.

\subsection{O Sistema africano: órgãos e funções}

Na tentativa de melhor tutelar os direitos no continente africano, surgiu o sistema africano de proteção aos direitos humanos, composto pela comissão e corte africana de direitos humanos. A primeira, por sua vez, atua como um órgão de supervisão, mediante a legitimidade de sua competência ${ }^{10}$, através da análise de relatórios dos Estados frente a violações de direitos salvaguardados pela Carta Africana.

${ }_{8}$ Ver mais: Franz Matscher. Quarante ans d'activités de la Cour Européenne des Droits de l'Homme, p. 251.

9 Estes autores elucidaram uma forte crítica doutrinaria sobre as funções do Comitê de ministros da Europa, indicando em seus estudos que este órgão (que teve suas funções modificadas pelo protocolo $\mathrm{n}^{\circ} 11$ ) não poderia continuar a ter uma competência contenciosa, mas tão somente uma função supervisional, como forma de não se ultrapassar a função precípua do tribunal. Assim, com o advento do protocolo $n^{\circ} 11$, extinguiu essa competência contenciosa do comitê e preservaram a função supervisional das decisões, passando a corte possuir função exclusiva de decidir ou não se houve violações de direitos nos casos contenciosos.

${ }^{10}$ A comissão, ainda, exercerá uma competência de natureza interpretativa, conforme dispõe o art. 45, III da Carta de Banjul, onde delega a comissão africana a responsabilidade de realizar interpretações teóricas a cerca dos dispositivos, a pedido dos Estados-parte, seus órgãos, ou até de organizações reconhecidas pela União Africana. 
A denominada Organização da Unidade Africana (OUA) surgiu de um tratado celebrado no dia 25 de maio de 1963, em Adis-Abeba, Etiópia, com assinatura dos representantes de 32 governos. Posteriormente, outros 21 Estados assinaram o tratado ${ }^{11}$.

A fundação da OUA se dá por fatos históricos ligados a um momento no qual o continente africano passava pelo processo de descolonização, lutava contra a discriminação racial e formação do direito dos povos africanos de disporem de seus próprio destino, ou seja, lutam pela autodeterminação.

A corte africana será o órgão responsável por exercer sua competência contenciosa e executiva, seguindo a mesma lógica da Corte Europeia e Interamericana de direitos humanos.

Objetivando a promoção dos direitos humanos, tanto a Comissão quanto a Corte africana, atuam sob escopo da Carta Africana e dos protocolos adicionais, visando à proteção de direitos humanos.

\subsubsection{A corte africana de justiça}

Este órgão, cujo objetivo é de cumprir a função judicial da União africana, é composto por onze juízes nacionais dos Estados-parte. Sua competência é voltada a interpretar, aplicar e validar os tratados internacionais concluindo no âmbito africano, de maneira que, também possui como responsabilidade, garantir a efetiva evolução dos direitos humanos no sistema judicial africano.

\subsubsection{A comissão africana dos direitos humanos e dos povos}

O nascimento deste órgão ${ }^{12}$ foi um avanço para a defesa dos direitos humanos no continente africano, embora seja considerado um órgão recomendatório.

É composta por onze membros eleitos pela Assembleia de chefes do Estado e governo da União Africana, sob o mandato de seis anos. A funcionalidade da comissão africana ocorre através de, no mínimo, duas sessões ordinárias anuais, na sede da Comissão em Banjul, Gambia.

Dentre suas funções previstas pela carta africana, está a de supervisão, onde há a análise das decisões, de maneira que sua marca está estampada pela promoção dos direitos humanos.

\footnotetext{
${ }^{11}$ Carta Africana dos Direitos humanos e dos povos. Disponível em: < http:www.dhnet.org.br/direitos/ sip/áfrica/banjul.htm> Acesso em 24 de out. de 2013.

${ }^{12}$ Este órgão adveio com o regulamento contido no art. 30 da Carta africana.
} 
Embora sua competência seja limitativa, cabe a comissão analisar os relatórios periódicos apresentados pelos Estados, investigar possíveis violações de direitos humanos e aqueles previstos na carta africana, bem como elaborar relatórios conclusivos sobre as denúncias que recebem mensalmente ${ }^{13}$.

Outra competência importante é a interpretativa ${ }^{14}$, onde se visualizou um objetivo teórico de aperfeiçoamento da estrutura e funções do sistema africano, sob égide, de cada vez mais, criar entendimentos a pro direitos humanos.

\subsubsection{A corte africana de direitos humanos}

A corte africana de direitos humanos, estudada enquanto sua composição, competência, mecanismos processuais e particularidades deste órgão, formando o presente estudo e concluindo a finalidade a ele destinado.

Estudou-se, também, a correlação entre os órgãos do presente sistema, com a corte africana de justiça, órgão criado recentemente e com funções importantes de serem analisadas.

\subsubsection{Composição}

A corte africana de direitos humanos, segundo o art. 11 do protocolo adicional da carta de Banjul, será composta por onze membros que deverão ser nacionais dos Estados que compõe a União Africana. A eleição que procederá a composição da corte seguirá as observações e requisitos jurídicos no campo dos direitos humanos, devendo-se obedecer ao limite máximo de 03 (três) candidatos indicados por país.

\subsubsection{Competência}

A competência da corte africana para analisar denúncias e casos de violações de direitos humanos será contenciosa e consultiva, conforme estabelece os artigos 3 e 4 do protocolo adicional a carta africana.

\footnotetext{
${ }^{13}$ Vislumbra-se que a conclusão e resultado de todo esse processo funcional desempenhado pela comissão africana, direcione as recomendações e sugestões, tanto aos Estados-membros, como a Assembleia da União Africana, a fim de que sejam tomadas as providencias cabíveis.

${ }^{14}$ A competência interpretativa, atribuída no art. 45, III da Carta de Banjul, remonta que competirá a este órgão a função de eventuais interpretações a respeito de seus dispositivos, podendo, então, faze-la mediante requisição dos Estados-parte, de seus órgãos e até de outras organizações não estatais reconhecidas pela União Africana.
} 
A competência contenciosa da Corte africana se subdivide em competência ratione personae e ratione materiae. A primeira se direciona a legitimidade de se apresentar demandas a Corte, sendo expresso o protocolo ao estender esta competência a Comissão africana, Estados signatários do protocolo, bem como instituições africanas que possuam faculdade para tal. Assim, no sistema africano, os indivíduos podem levar suas demandas até a Corte $^{15}$ e buscarem justiça pelas cogitáveis violações aos direitos humanos.

De outro modo, a ratione materiae, elencada no art. 3 do protocolo adicional a Carta africana, estabelece que nos casos submetidos a cortes, deverá ser definida a competência segundo os ditames legais contidos nos instrumentos internacionais.

Existe ainda, a competência consultiva da corte, podendo ela emitir parecer sobre qualquer temática jurídica indicada e prevista na Carta Africana, bem como sobre qualquer outro instrumento internacional que verse sobre direitos humanos.

\subsection{Considerações Finais: Uma comparação entre os sistemas regionais $^{16}$}

Os sistemas regionais abrangem três domínios: O americano, europeu e africano, cada um com suas responsabilidades na proteção dos direitos humanos frente aos Estados.

As organizações institucionais nos sistemas regionais têm função de ingerir administrativamente a tutela dos direitos humanos, bem como o acesso à justiça. No âmbito africano, temos a Organização da unidade Africana (OUA), que foi substituída em 2002 pela União Africana em 2002, contando com 53 membros. No âmbito interamericano, temos a Organização dos Estados Americanos (OEA), fundada em 1948 e com 35 membros. Na Europa, temos o Conselho da Europa (CE), fundada em 1949 e com 46 membros.

A base legal que rege o sistema africano é composta pela Carta Africana de direitos humanos e dos povos, com 53 ratificações; Protocolo adicional a Carta Africana de direitos humanos e dos povos ${ }^{17}$, criada em 1998 e com 21 ratificações. Igualmente temos o sistema interamericano, que conta com a

\footnotetext{
${ }^{15}$ Contudo, a competência ratione personae atribuída ao indivíduo de postular perante a Corte não é absoluta, devendo os Estados-partes dos nacionais se declararem, de maneira expressa, submissos a demanda individual.

${ }^{16}$ Ver mais: http://www.scielo.br/pdf/sur/v3n4/09.pdf (Acesso em 23/10/2013)

${ }^{17}$ Embora tenha sido criada em 1998, entrou em vigor em 2004.
} 
carta da OEA e a Declaração Americana dos direitos e deveres do homem, ambas criadas em 1948, contando com 51 ratificações; Convenção americana dos Direitos humanos, criada em 1969, com 24 ratificações e dentre estes somente 21 aceitaram a competência contenciosa da corte. No âmbito europeu, temos a convenção para a proteção de direitos humanos e liberdades fundamentais, com 45 ratificações.

No sistema africano, anualmente são decididos 10 casos. No interamericano, a Corte decide de 4 a 7 casos por ano. Na Europa, por sua vez, são decididos milhares de casos anualmente.

\section{CONSIDERAÇÕES FINAIS}

Embora a razão que tenha conduzido a criação dos sistemas regionais de proteção aos direitos humanos, provocar, na maioria dos incidentes que atuam, uma reflexão sobre os direitos violados no passado ${ }^{18}$, causou, também a expansão doutrinária e acadêmica sobre a preocupação com os direitos humanos e suas particularidades.

A partir do surgimento do direito internacional dos direitos humanos, a tutela dos direitos inerentes aos seres humanos deixa de ser matéria afetada exclusivamente em favor do direito constitucional, que se mostrou inapto para, sozinho, assegurar tais direitos em face da atuação beliciosa dos estados na fase anterior a Declaração Universal. O direito internacional, então, assume tal escopo em responsabilidade partilhada com o direito constitucional, e a comunidade universal passa a agir como um limitador da voluntariedade das relações dos estados com seus súditos, reconhecendo a personalidade jurídicointernacional do individuo.

Deste modo, através do caminho percorrido, encontramos particularidades que sinalizaram diversos vetores que comprovam a importância e relevância do tema discutido. A perspectiva de algumas questões, como a natureza histórica e a evolução dos direitos humanos e dos sistemas regionais, serviram como substrato para a exigibilidade da proteção nacional e internacional aos direitos basilares do ser humano.

Com efeito, a questão dos direitos humanos e sua evolução dentro dos sistemas regionais de proteção aos direitos humanos, possuíram, em sua essência,

\footnotetext{
${ }^{18}$ Abre-se o parênteses para citar a criação da Comissão da Verdade, órgão que possui uma função de investigação de possíveis violações de direitos humanos na época ditatorial, incidindo como reflexo da importância, no passado, de se pensar sobre os direito fundamentais a vida humana.
} 
a latente problemática relacionada à busca de soluções eficazes e seguras contra as violações de direitos humanos, mapeando, deste modo, no estudo das funções desempenhadas pelos órgãos de cada sistema regional.

A criação de sistemas específicos é saudada pela doutrina internacional e esse é nosso entendimento, devido principalmente as especificidades encontradas. Na África, por exemplo, as questões tribais são pouco conhecidas pelos outros continentes, como a presença de membros da etnia Hutu em Ruanda e Burrundi e alguns poucos na Zâmbia. O confronto entre fundamentalistas islâmicos e os cristãos e também com os minimalistas é outro dos problemas específicos daquele continente.

No âmbito das Américas, a presença de centenas de tribos indígenas e negros quilombolas já justificaria um sistema regional, mas em democracias ainda jovens, há outros problemas, que ficam patentes nas análises dos julgamentos feitos pela Corte Interamericana de Direitos Humanos.

\section{REFERÊNCIAS}

\section{AMARAL JR., Alberto do. A proteção internacional dos direitos}

humanos. Revista de informação legislativa, ano 39, n. 155, julh/set., 2002.

ARRIGHI. Jean Michel. OEA. Organização dos Estados Americanos. Trad. Sérgio Bath. Barueri: Manole, 2004.

ARRUDA, Eloísa de Souza. O papel do Ministério Público na efetivação dos tratados internacionais de direitos humanos. São Paulo: Pontifícia Universidade Católica de São Paulo, 2008 (Tese de doutorado).

BOBBIO. Norberto. A era dos direitos. Rio de Janeiro: Elsevier, 2004.

CANÇADO TRINDADE. Antônio A. A proteção internacional dos Direitos Humanos. São Paulo: Saraiva, 1991.

. Tratado de direito internacional dos direitos humanos.

Vol III. Porto Alegre: Sergio Antônio Fabris, 2003.

DELLA COSTA, Emiliano Humberto. A corte interamericana de Direitos Humanos e o Brasil. Curitiba: Juruá, 2004, 537 p.. ISBN: 85-362-0784-1 
FIX-SAMUDIO. Hector. Protección jurídica de los derechos humanos. México: Comisión Nacional de Derechos Humanos, 1991.

. Protección jurídica de los derechos humanos. In: Flávia Piovesan. Direitos Humanos e o Direito Constitucional Internacional. $2^{\circ}$ ed. São Paulo: Max Limonad, 1997.

GOMES, Luiz Flávio; PIOVESAN, Flavia; TRINDADE, Antônio Augusto Cançado; DULITZKY, Ariel E.; GALLI, Maria Beatriz; MELO, Monica de; PFEIFFER, Roberto Augusto Castellanos; KRSTICEVIC, Viviana. $O$ sistema interamericano de proteção aos direitos humanos e o direito brasileiro. São Paulo: Revista dos tribunais, 2000. 466p. ISBN 85-203-1952-1.

MAZZUOLI, Valério de Oliveira. O Brasil e o Sistema Interamericano de proteção dos direitos humanos, in Novos Rumos do direito penal contemporâneo: livro em homenagem ao Prof. Dr. Cezar Roberto Bitencourt. André Zenkner (coord.). Rio de Janeiro: Lumen Juris,2006.

HERKENHOFF. João Baptista. Direitos Humanos: a construção universal de uma utopia: a dialética dos direitos humanos. São Paulo: Santuário, 1997. ISBN: 85-7200-455-6.

JAYME. Fernando G. Direitos Humanos e a sua efetivação pela corte interamericana de Direitos Humanos. Belo Horizonte: Del Rey, 2005.

LAFER, Celso. A internacionalização dos direitos humanos: $\mathrm{O}$ desafio do direito a ter direitos. In. Odilio Alves Aguiar; Celso de M. Pinheiro; Karen Franklin. (org). 'Filosofia e Direitos Humanos'. Fortaleza: UFC, 2006. $4^{\mathrm{o}}$ vol.

LUCHAK, Danièle. Les droits de l'homme. Paris: La Découvert, 2005

MAHONEY, Paul; PREBENSEN, Soren. The European Court of Human Rights: The European system for the protection of human rights. Dordrecht: Martinus Nijhoff,1993 
MATSCHER, Franz. Quarante ans d'activités de la Cour Européenne des Droits de'l Homme. Recueil des Cours, vol. 270, 1997.

MAZZUOLI. Valério de Oliveira. Direitos Humanos e cidadania: a luz do novo Direito Internacional. Campinas: Minelli, 2002. ISBN: 85-888-8406-2.

. Curso de direito internacional público, $4^{\circ} \mathrm{ed}$. rev., atual. e ampl. São Paulo: TR, 2009.

MIRANDA, Jorge. Curso de direito internacional público: uma visão sistemática do direito internacional dos nossos dias, $4^{\circ}$ ed. Rio de Janeiro: Forense, 2009.

PEREIRA. André Gonçalves; QUADROS. Fausto. Manual de Direito internacional público. $3^{\circ}$ ed., Coimbra: Almedina, 1993.

PIOVESAN, Flávia. Direitos Humanos e o Direito Constitucional Internacional. 7ed. São Paulo: Saraiva, 2007.

. Direitos humanos e justiça internacional: um estudo comparativo dos sistemas regionais europeu, interamericano e africano. São Paulo: Saraiva,2006.

PORTELA, Paulo Henrique Gonçalves. Direito Internacional público e privado incluindo noções de direitos humanos e de direito comunitário. Salvador: JusPODIVM, 2009. 826p. ISBN: 85-7761-244-9.

RAMOS, André de Carvalho. Direitos Humanos em juízo: comentários aos casos contenciosos e consultivos da Corte Interamericana de Direitos Humanos. São Paulo: Max Limonad, 2001.

. Processo Internacional dos direitos humanos: análise dos sistemas de apuração de violações dos direitos humanos e a implementação das decisões no Brasil. Rio de Janeiro: Renovar, 2002.

REZEK. José Francisco. Direito Internacional Público. São Paulo: Saraiva, 1989 
TEIXEIRA, Jonatas Eduardo Batista Martins. Sistema interamericano de Direitos Humanos: Um mecanismo regional suplementar de proteção internacional dos direitos humanos. 2011, 156 f. Monografia (Graduação de Direito) - Faculdades Integradas “'Antônio Eufrásio de Toledo", Faculdade de Direito de Presidente Prudente, 2011.

Artigo recebido em: 10/04/2014 Aprovado para publicação em: 12/08/2014

Como citar: TIBIRIÇA, Sérgio. FARAH, Giovana Eva Matos. Sistemas regionais de proteção aos direitos humanos: aspectos fundamentais . Revista do Direito Público. Londrina, v.9, n.2, p.25-39, mai./ago.2014. DOI: 10.5433/1980-511X.2014v9n2 p25. 